\title{
The mGluR2/3 Agonist LY379268 Blocks the Effects of GLT-I Upregulation on Prepulse Inhibition of the Startle Reflex in Adult Rats
}

\author{
Michele Bellesi' and Fiorenzo Conti*,1,2 \\ 'Dipartimento di Neuroscienze, Università Politecnica delle Marche, Ancona, Italy; ${ }^{2}$ Fondazione di Medicina Molecolare, Università Politecnica \\ delle Marche, Ancona, Italy
}

\begin{abstract}
The main glutamate transporter GLT-I is responsible for clearing synaptically released glutamate from the extracellular space and contributes to the shaping of glutamatergic transmission. Recently, it has been shown that ceftriaxone (CEF)-induced GLT-I upregulation is associated with an impairment of the prepulse inhibition (PPI) of the startle reflex, a simple form of information processing that is reduced in schizophrenia, and determines a strong reduction in hippocampal metabotropic glutamate receptor (mGluR)2/3-dependent long-term depression. In this study, we tested the hypothesis that administration of the mGluR2/3 agonist LY379268 blocks the effect of GLT-I upregulation on PPI of the startle. We showed that administration of LY379268 (I mg/kg) prevented PPI alterations associated with GLT-I upregulation, suggesting that CEF-induced PPI impairment was mGluR2/3 dependent. In addition, we showed that CEF-induced GLT-I upregulaton did not alter the expression of mGluR2/3, and also that it occurred at sites of mGluR2/3 expression. These results indicate a novel mechanism by which GLT-I upregulation modulates PPI of the startle.

Neuropsychopharmacology (2010) 35, 1253-1260; doi:I0.1038/npp.2009.225; published online 13 January 2010
\end{abstract}

Keywords: glutamate transporters; GLT-I; metabotropic glutamate receptors; prepulse inhibition

\section{INTRODUCTION}

GLT-1 (EAAT2; SLC1A2), the main glutamate transporter in the mammalian forebrain, is responsible for the largest proportion of total glutamate transport (Rothstein et al, 1996; Tanaka et al, 1997; Conti and Weinberg, 1999; Danbolt, 2001). Owing to its perisynaptic localization (Rusakov and Lehre, 2002; Melone et al, 2009a), GLT-1 regulates glutamate spillover, thereby modulating the activation of glutamate receptors (Scanziani et al, 1997; Min et al, 1998; Mitchell and Silver, 2000; Tzingounis and Wadiche, 2007).

For its fundamental role in regulating Glu levels, GLT-1 is involved in the pathophysiology of several neuropsychiatric diseases (Beart and O'Shea, 2007; Lauriat and McInnes, 2007; Sheldon and Robinson, 2007). Some evidence suggests a role for GLT-1 in the pathophysiology of schizophrenia as follows: (1) a susceptibility locus for schizophrenia is probably located within or near the GLT-1 gene (Deng et al, 2004), and this gene is reportedly dysregulated in patients

*Correspondence: Dr F Conti, Dipartimento di Neuroscienze, Università Politecnica delle Marche, Via Tronto I0/A, Torrette di Ancona, I-60020 Ancona, Italy, Tel: + 39 07| 220 6056, Fax: + 3907 I 220 6052, E-mail: f.conti@univpm.it

Received 22 October 2009; revised 2 December 2009; accepted 7 December 2009 with schizophrenia (Shao and Vawter, 2008); (2) GLT-1 immunoreactivity is increased in the thalamus, striatum, and prefrontal cortex of schizophrenia patients (Matute et al, 2005; McCullumsmith and Meador-Woodruff, 2002; Smith et al, 2001); (3) the antipsychotic clozapine specifically downregulates GLT-1 expression and function both in vivo and in vitro (Melone et al, 2001, 2003; VallejoIllarramendi et al, 2005); (4) the psychotomimetics PCP specifically upregulates GLT-1 expression and function (Fattorini et al, 2008); and (5) pharmacologically induced GLT-1 upregulation is associated with an impairment of the prepulse inhibition (PPI) of the startle reflex, a neurophysiological parameter altered in schizophrenia patients and in animal models of schizophrenia, in a dihydrokainate (DHK)-reversible manner, and worsens PCP-induced PPI alterations (Bellesi et al, 2009; Melone et al, 2009b). These data support the hypothesis that, in concert with both NMDARs and non-NMDARs (Lewis and Gonzalez-Burgos, 2006; Lewis and Moghaddam, 2006), GLT-1 has a role in the dysfunction of glutamatergic transmission that contributes to the disturbance of information processing occurring in schizophrenia (Venables, 1960; McGhie and Chapman, 1961; Andreasen, 1997, 2000; Tononi and Edelman, 2000).

Targeting metabotropic glutamate receptors (mGluRs) is a practical strategy for regulating abnormal glutamatergic transmission (Moghaddam, 2004). The selective mGluR2/3 agonist LY379268 attenuates behavioral abnormalities in 
animal models of schizophrenia, and its analog LY404039 is effective in a schizophrenia phase 2 clinical trial (Cartmell et al, 1999, 2000; Clark et al, 2002; Imre et al, 2006; Imre, 2007; Patil et al, 2007; Harrison, 2008). Recently, we have shown that ceftriaxone (CEF)-induced GLT-1 upregulation impairs hippocampal long-term depression (LTD) in a DHK-reversible manner by limiting activation of mGluR2/3, thus indicating that a reduced function of mGluR2/3 mediates the effects of GLT-1 upregulation (Omrani et al, 2009).

In this study, we tested the hypothesis that administration of the selective mGluR2/3 agonist LY379268 blocks the impairment of PPI of the startle reflex associated with GLT-1 upregulation.

\section{MATERIALS AND METHODS}

\section{Animals \\ Adult Sprague-Dawley male rats (initial weight 280-300 g; Charles River, Milano, Italy) were used. Their care and handling were approved by the Ethical Committee for Animal Research of Università Politecnica delle Marche. Experiments were carried out in accordance with the European Communities Council Directive (86/609/EEC), and all efforts were made to minimize animal suffering and to reduce the number of animals used. Animals were kept under a 12-h dark-light cycle and permitted food and water ad libitum. Rats were caged in pairs and handled within $24 \mathrm{~h}$ of arrival and then over at least 1 week before testing; to minimize stress during behavioral testing, rats were briefly handled before any procedure (Geyer and Swerdlow, 1998).}

\section{Drugs and Treatments}

CEF sodium (CEF, Rocefin, Roche, Milano, Italy) was used to upregulate GLT-1 (Rothstein et al, 2005; Bellesi et al, 2009; Omrani et al, 2009). CEF was dissolved in saline $(0.9 \%$ $\mathrm{NaCl}$ ) and administered intraperitoneally (i.p.) at a dose of $200 \mathrm{mg} / \mathrm{kg}$ for 8 consecutive days (Bellesi et al, 2009). LY379268 (2453, Tocris Bioscience, Bristol, UK) was dissolved in saline and administered i.p. in a single dose of $1 \mathrm{mg} / \mathrm{kg}$ at day 10 , ie, 2 days after CEF withdrawal. Control rats, matched for age, sex, and weight, received saline i.p. All injections were administered between 1000 and 1100 hours.

\section{PPI of the Startle Reflex}

Experimental design. Four experimental groups $(n=11$ for each group) were studied: the first group received saline for 8 days, followed 2 days after by a single injection of saline (Saline group); the second group received saline for 8 days, followed 2 days after by a single injection of LY379268 (saline + LY group); the third group received CEF for 8 days, and an injection of saline 2 days after CEF withdrawal (CEF group); and the fourth group was administered CEF for 8 days, followed by a single injection of LY379268 2 days after CEF withdrawal (CEF + LY group). All acoustic startle experiments were conducted in an acoustic startle chamber (SR-LAB; San Diego Instruments, San Diego, CA, USA). Two days before treatment inception, a brief startle session was performed to obtain experimental and control groups matched for startle reactivity (matching session; Geyer and Swerdlow, 1998; Martinez et al, 1999). In all experimental groups, PPI test was conducted at day 10 (2 days after CEF withdrawal) to allow complete clearance of the antibiotic (Rebuelto et al, 2003), $30 \mathrm{~min}$ after the injection of saline or LY379268.

Testing procedures. For matching startle sessions, rats were placed in a startle chamber and exposed to $5 \mathrm{~min}$ of $70-\mathrm{dB}$ background noise, followed by 11 pulse-only trials (40-ms noise burst at $120 \mathrm{~dB}$ ); intertrial interval was $15 \mathrm{~s}$ (Geyer and Swerdlow, 1998).

The PPI session lasted $\sim 14 \mathrm{~min}$, and consisted of $5 \mathrm{~min}$ of acclimation (70- $\mathrm{dB}$ background), followed by 4 trial types: pulse-only trials (40-ms noise burst at $120 \mathrm{~dB}$ ) and 3 prepulse trials $(20-\mathrm{ms}$ noise bursts 3,6 , or $12 \mathrm{~dB}$ above background, followed $100 \mathrm{~ms}$ later by a $40-\mathrm{ms}$ noise burst at $120 \mathrm{~dB}$ ). Sessions included 3 blocks: block 1 (6 pulse-only trials), block 2 (10 pulse-only trials and 5 prepulse trials for each prepulse tone presented in a pseudorandom order), and block 3 (5 pulse-only trials). The intertrial interval was $15 \mathrm{~s}$.

Data collection and analysis. Experimental groups were matched for startle reactivity, which was calculated by averaging pulse-alone startle amplitude (2-11 trials) of each animal during matching session (Geyer and Swerdlow, 1998).

In all animals, startle reflex magnitude was measured by averaging the startle amplitude of pulse-only trials of block 2 (10 trials). The degree of PPI (in \%) was calculated according to the formula: PPI $=100 \times$ (pulse-only units(prepulse + pulse units))/(pulse-only units) (Geyer and Swerdlow, 1998), where pulse-only units were startle magnitudes recorded from block 2. Habituation was assessed as the decrement in response magnitude across blocks (block 1, trials 2-6 and block 3, trials 32-36).

\section{Western Blotting}

After completion of PPI studies (ie, at day 10), 4 control rats and 4 CEF-treated rats were anesthetized with chloral hydrate $(300 \mathrm{mg} / \mathrm{kg}$ i.p.) and decapitated; the brains were dissected and the frontal cortex, hippocampus, and striatum were removed. Homogenization and crude synaptic plasma membrane preparation were carried out as described previously (Danbolt et al, 1990). Bio-Rad Protein Assay (Bio-Rad Laboratories, GmbH, München, Germany) and a Beckman DU 530 spectrophotometer (Beckman Coulter, Fullerton, CA, USA) were used to determine the total amount of protein in each homogenate (3-4 measurements per homogenate). A standard curve with $2,4,6,8$, and $10 \mu \mathrm{g}$ of bovine serum albumin (A4503, Sigma Chemicals, St Louis, MO, USA) was drawn for each dosing run. As housekeeping proteins (such as $\alpha$-actin and $\beta$-tubulins) are sensitive to experimental treatments (particularly pharmacologic treatments) and to diverse physiological conditions and have therefore some limitations as internal standard (Ferguson et al, 2005), 3-6 measurements were made for each brain region of each animal; to minimize procedural variables, homogenates from treated and control animals 
were loaded onto the same gel (Bragina et al, 2006). For a semi-quantitative analysis, we drew standard curves of increasing concentration of total protein from controls $(n=4)$ to define a linear range for immunoblot densitometric analysis (Bragina et al, 2006). Nitrocellulose filters were probed with mGluR2/3 antibodies (AB1553; Millipore, Billerica, MA, USA; $1: 200 ; 20 \mu \mathrm{g}$ of total protein; Testa et al, 1998). After exposure to secondary antibodies (Vector, Burlingame, CA, USA), bands were visualized by Bio-Rad Chemidoc and Quantity One software using the SuperSignal West Pico (Rockford, IL, USA) chemiluminescent substrate (see Bragina et al, 2006 for details).

\section{Immunocytochemistry}

After completion of PPI studies (day 10), 4 control rats and 4 CEF-treated rats were anesthetized with chloral hydrate $(300 \mathrm{mg} / \mathrm{kg}$ i.p.) and perfused transcardially with a flush ( $\sim 1 \mathrm{~min}$ ) of saline, followed by $4 \%$ paraformaldehyde in phosphate buffer $(\mathrm{PB})$. The brains were removed, postfixed in the same fixative for 7 days (Chen et al, 2004), and cut on a Vibratome in $50-\mu \mathrm{m}$ parasagittal sections, which were collected in $\mathrm{PB}$ in serial groups of 5 and then used for immunocytochemistry (Minelli et al, 2001; Chen et al, 2004; Melone et al, 2005). Sections were incubated in a solution containing a mixture of GLT-1 (1:1000; Millipore; AB1783; Bragina et al, 2006) and mGlurR-2/3 (1:50; Millipore; AB1553; Testa et al, 1998) primary antibodies. Sections were then exposed to a solution containing a mixture of affinitypurified fluorescein isothiocyanate (1:250; Vector; FI1000/ J0114)- or tetramethylrhodamine isothiocyanate $(1: 250$; Molecular Probes, PoortGebouw, The Netherlands, T-2762/ 6691-1)-conjugated secondary antibodies. Sections were washed, mounted, air-dried, and coverslipped using the Vectashield mounting medium (H-1000; Vector), and finally examined with a Leica TCS SL confocal laser scanning microscope equipped with an argon $(488 \mathrm{~nm})$ and helium/ neon $(543 \mathrm{~nm})$ laser. Control experiments with singlelabeled sections and sections incubated with two primary antibodies and one secondary antibody or with one primary and two secondary antibodies revealed neither bleedthrough nor cross-reactivity. For all immunocytochemical studies, sections from controls and CEF-treated animals were processed in parallel to minimize procedural variables.

Data collection and analysis. Fields from layers II to III of the frontal neocortex anterior to the bregma, from the stratum lucidum of hippocampal CA1, and from the striatum of control $(n=4)$ and CEF-treated $(n=4)$ animals were randomly selected for each fluorescent as $1024 \times 1024$ pixel images with a planapo $\times 63$ objective (numerical aperture 1.4) and pinhole 1.0 Airy unit. To improve the signal-noise ratio, 8 frames of each image were averaged; microscopic fields were scanned with a pixel size of $80 \mathrm{~nm}$. Quantitative analysis of puncta staining was performed in randomly selected $8 \times 8 \mu \mathrm{m}^{2}$ fields from each $1024 \times 1024$ pixel image (10 fields for each region for each animal). Image processing was performed on Photoshop CS2 (Adobe Systems, San Jose, CA, USA); optimal resolution of punctate staining was obtained by setting threshold values as described elsewhere (Bellesi et al, 2009). Threshold values did not differ across conditions (ie, between control and treated groups). After thresholding, images were transformed in binary images using the Image J software (v.1.38, $\mathrm{NIH}$, USA.) (Bragina et $a l, 2006)$ and the mean size and number of mGluR2/3 and GLT-1 puncta was calculated. To verify whether GLT-1 upregulation occurred at sites where mGluR2/3 was expressed, the mean size of GLT-1 puncta contacting mGluR2/3 puncta (a contact was defined as the presence of fluorescence signals overlap) was estimated.

\section{Statistical Analysis}

Startle reactivity was analyzed using one-way ANOVA. Startle reflex magnitudes were analyzed using two-way ANOVA with CEF and LY379268 as between-subject factors. PPI scores were analyzed using three-way ANOVA with prepulse intensities as a within-subject factor and CEF and LY379268 as between-subject factors. Habituation was analyzed with three-way ANOVA with block as a withinsubject factor and CEF and LY379268 as between-subject factors. In the presence of interaction, pairwise comparisons were conducted with two-way ANOVA with CEF or LY379268 as a between-subject factor and prepulse intensity or block as a within-subject factor. For multiple comparisons, $\alpha$ was set at 0.01 . Statistical significance for western blotting and immofluorescence studies was evaluated by two-sided $t$-test $(\alpha=0.05)$. Statistical analysis was performed using SPSS (v.13.0).

\section{RESULTS}

\section{Effects of LY379268 on PPI Impairment Induced by CEF Treatment}

Mean values of startle reactivity in all experimental groups were $95.3 \pm 10.5$ for the Saline group, $83.8 \pm 10.3$ for the saline + LY group, $94.2 \pm 14.9$ for the CEF group, and $80.9 \pm 14.4$ for the CEF + LY group. One-way ANOVA did not reveal any significant difference among the four groups $(\mathrm{F}((3,40)=0.44 ; \mathrm{NS}))$.

Effects on startle magnitude. CEF treatment and a single LY379268 injection had no significant effect on startle magnitude (Table 1). Two-way ANOVA of startle magnitude with CEF and LY379268 as between-subject factors revealed neither significant effects of $\operatorname{CEF}(F(1,40)=0.02$; NS) and LY379268 $(\mathrm{F}(1,40)=0.12$; NS) nor CEF $\times$ LY379268 interaction $(\mathrm{F}(1,40)=0.15$; NS).

Effects on PPI. LY379268 blocked PPI impairment induced by CEF administration (Figure 1). Three-way ANOVA of PPI with CEF and LY379268 as between-subject factors and prepulse intensity as a within-subject factor showed a significant effect of $\operatorname{CEF}(\mathrm{F}(1,40)=14.96 ; P<0.0001)$ and LY379268 $(\mathrm{F}(1,40)=8.07 ; P=0.007)$, a significant $\mathrm{CEF} \times$ LY379268 interaction $(\mathrm{F}(1,40)=17.52 ; P<0.0001)$, and a significant effect of prepulse intensity $(\mathrm{F}(2,80)=95.3$; $P<0.0001)$. Prepulse intensity $\times$ CEF, prepulse intensity $\times$ LY379268, or prepulse intensity $\times$ CEF $\times$ LY379268 interactions were not significant. For defining CEF $\times$ LY379268 interaction, we evaluated pairwise comparisons among the different treatment conditions. Comparison of group Saline and group CEF with two-way ANOVA, with CEF as a 
Table I Startle Reflex Magnitude and Habituation (Mean \pm SEM) of Experimental Groups

\begin{tabular}{lccc}
\hline & $\begin{array}{c}\text { Startle magnitude } \\
\text { second trial block }\end{array}$ & \multicolumn{2}{c}{ Habituation } \\
\cline { 3 - 4 } & & $\begin{array}{c}\text { First trial } \\
\text { block }\end{array}$ & $\begin{array}{c}\text { Last trial } \\
\text { block }\end{array}$ \\
\hline Saline group $(n=||)$ & $102.3 \pm 17.7$ & $134.5 \pm 21.8$ & $68.2 \pm 15.1$ \\
Saline+LY group $(n=||)$ & $92.6 \pm 25.8$ & $\mid 45.2 \pm 27.7$ & $73.5 \pm 12.9$ \\
CEF group $(n=||)$ & $98.9 \pm 18.7$ & $\mid 39.1 \pm 26.9$ & $84.9 \pm 22.5$ \\
CEF+LY group $(n=\mid 1)$ & $95.5 \pm 18.4$ & $152.3 \pm 38.7$ & $64.5 \pm 14.2$ \\
\hline
\end{tabular}

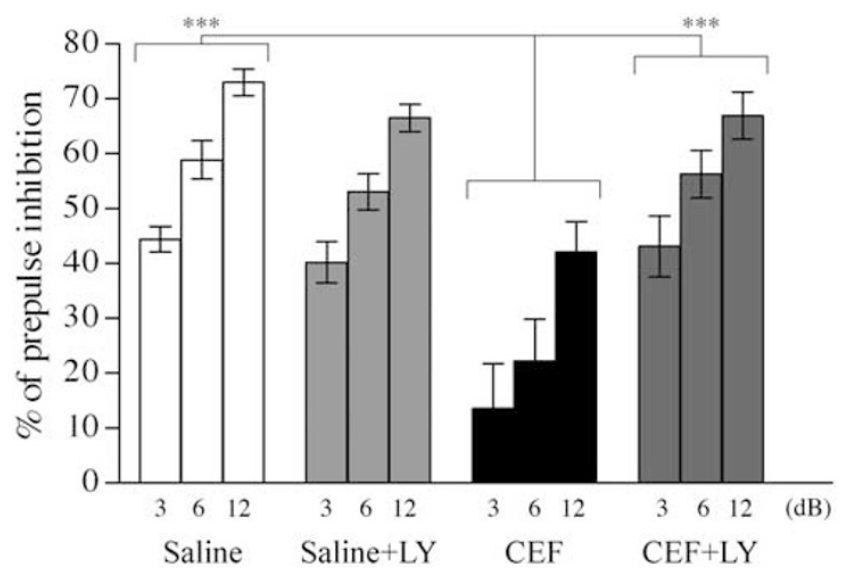

Figure I Acute administration of the selective mGlur-2/3 agonist LY379268 blocks PPI impairment associated with CEF treatment. Values are $\% \mathrm{PPI} \pm \mathrm{SEM} * * * * P<0.001$.

between-subject factor and prepulse intensity as a within subject factor, showed a significant effect of prepulse intensity $(\mathrm{F}(2,40)=41.83 ; P<0.0001)$ and of $\mathrm{CEF}(\mathrm{F}(1,20)=$ 25.71; $P<0.0001)$, but not of $\mathrm{CEF} \times$ prepulse intensity interaction $(\mathrm{F}(2,40)=0.57$; NS). Comparison of group Saline and group Saline/LY with two-way ANOVA, with LY379268 as a between-subject factor and prepulse intensity as a within-subject factor, showed a significant effect of prepulse intensity $(\mathrm{F}(2,40)=80.47 ; P<0.0001)$ but not of LY379268 $(\mathrm{F}(1,20)=2.58 ; \mathrm{NS})$ or of LY379268 $\times$ prepulse intensity interaction $(\mathrm{F}(2,40)=0.15$; NS). Comparison of group CEF and group CEF/LY with two-way ANOVA, with LY379268 as between-subject factor and prepulse intensity as within-subject factor, showed a significant effect of prepulse intensity $(\mathrm{F}(2,40)=33.11 ; P<0.0001)$ and of LY379268 $(\mathrm{F}(1,20)=14.96 ; P=0.001)$ but not of $L Y 379268 \times$ prepulse intensity interaction $(\mathrm{F}(2,40)=1.03$; NS).

Effects on habituation. CEF treatment and a single LY379268 injection had no effects on startle habituation to repeated acoustic pulses (Table 1). Three-way ANOVA of startle magnitudes, with CEF and LY379268 as betweensubject factors and trial block as a within-subject factor, revealed neither a significant effect of $\operatorname{CEF}(F(1,40)=0.25$; NS) and LY379268 $(\mathrm{F}(1,40)=0.01$; NS), nor a CEF $\times$ LY379268 interaction $(F(1,40)=0.12$; NS), but a significant effect of trial block $(\mathrm{F}(1,40)=57.06 ; P<0.0001)$. $\mathrm{CEF} \times$

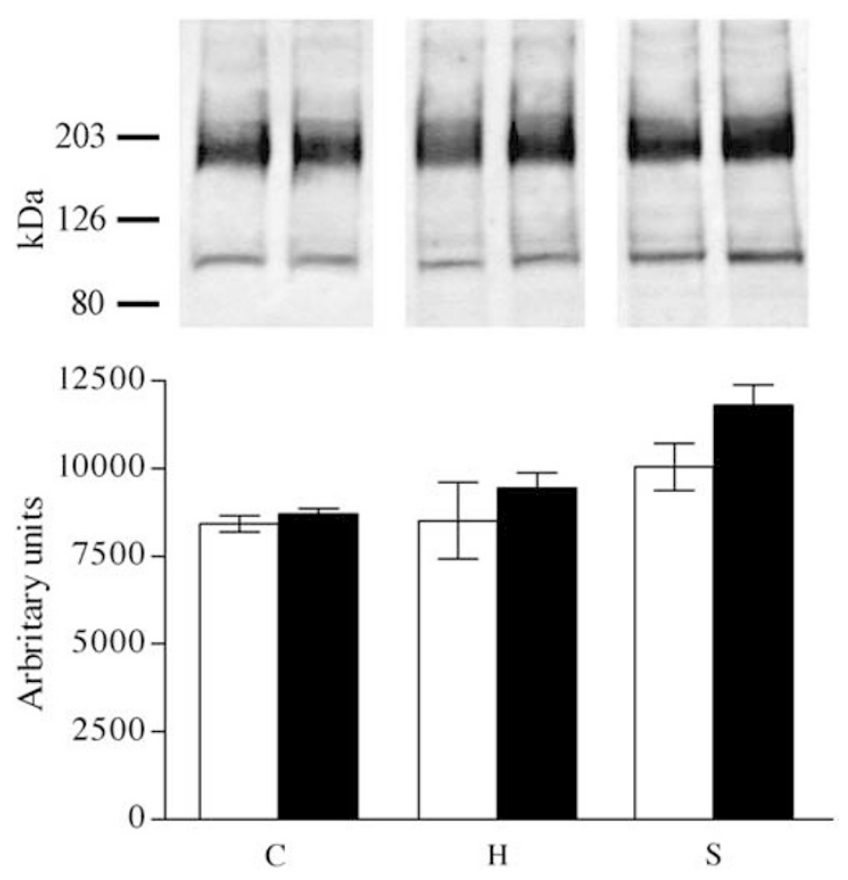

Figure 2 CEF treatment is not associated with alterations of mGluR-2/3 expression in forebrain regions regulating PPI. Western blotting studies do not reveal any significant difference between control (white column) and CEF-treated (black column) rats. C, frontal cortex; H, hippocampus; $\mathrm{S}$, striatum.

block, LY379268 $\times$ block, CEF $\times$ LY379268 $\times$ trial block interactions were not significant.

These studies showed that PPI alterations induced by CEF treatment were blocked by the selective mGluR2/3 agonist LY379268, indicating that reducing mGluR2/3 activation contributes to PPI impairment associated with CEF treatment.

\section{Effects of CEF Treatment on mGluR2/3 Expression}

To verify whether reduced activation of mGluR $2 / 3$ was associated with an alteration of its expression, we studied mGluR2/3 protein levels in forebrain regions regulating PPI (Swerdlow et al, 2001). In rats treated with CEF for 8 days, western blotting studies showed that mGluR2/3 expression was not significantly different from controls in the frontal cortex, hippocampus, and striatum, thus indicating that CEF treatment does not change the amount of mGluR2/3 expressed (Figure 2). In addition, to rule out the possibility that $\mathrm{CEF}$ altered the distribution of $\operatorname{mGluR} 2 / 3$, we carried out immunocytochemical studies in the same forebrain regions, and found that in CEF-treated rats, size and number of mGluR2/3 immunoreactive puncta were comparable with controls (Figure 3 ).

These results showed that PPI impairment induced by CEF treatment was not associated with an altered expression of mGluR2/3.

\section{Spatial Relationship Between GLT-1 Upregulation and mGluR2/3}

CEF treatment upregulates GLT-1 (Rothstein et al, 2005), and CEF-induced GLT-1 upregulation can be visualized immunocytochemically (Bellesi et al, 2009; Omrani et al, 

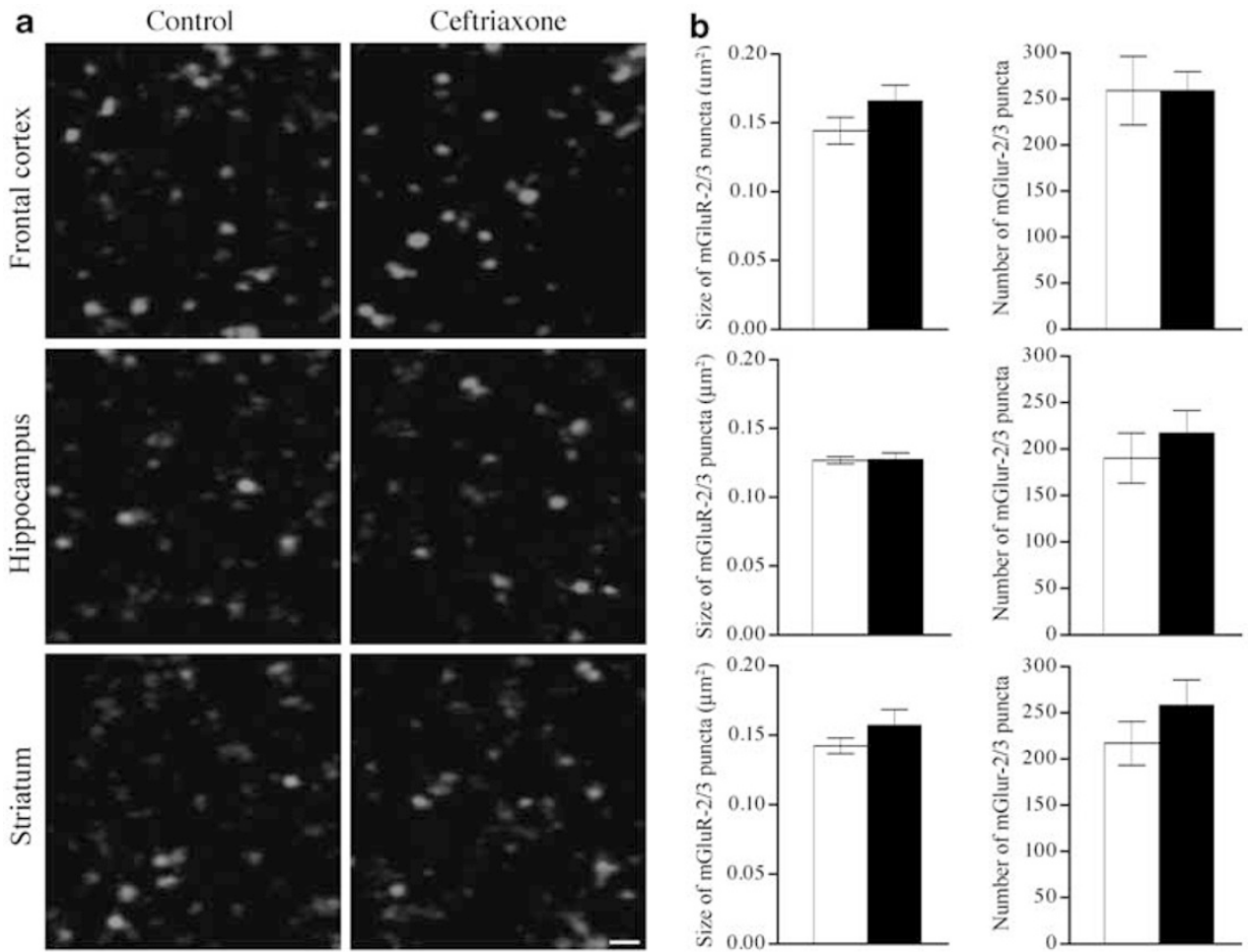

Figure 3 CEF treatment does not affect the distribution of mGlur-2/3 in the frontal cortex, hippocampus, and striatum. (a) $m G$ luR2/3 immunoreactive puncta in control and CEF-treated animals. Bar: $0.8 \mu \mathrm{m}$. (b) Quantitative analysis showed that mean size and number of mGluR2/3 puncta are comparable in control (white column) and CEF-treated (black column) rats. Values are mean \pm SEM.

2009). In this study, we measured the mean size of GLT-1 puncta in CEF-treated animals, and showed that it was significantly increased in the frontal cortex (by $49.9 \pm 12.9 \%$; $P=0.03$ ), hippocampus (by $46.2 \pm 10.8 \% ; P=0.03$ ), and striatum (by $93 \pm 26.1 \%$; $P=0.02$ ) compared with controls.

As both GLT-1 (Melone et al, 2009a) and mGluR2/3 (Ferraguti and Shigemoto, 2006) are localized perisynaptically, we sought to define the anatomical relationship between GLT-1 upregulation and mGluR2/3 expression.

In both controls and CEF-treated animals, confocal images showed a consistent degree of overlap between the two fluorescent signals, indicating a close spatial relationship between mGluR2/3 and GLT-1. To verify whether the increased expression of GLT-1 also occurs at the very sites expressing mGluR2/3, we estimated the mean size of GLT-1 puncta showing clear overlap with mGluR2/3 puncta (Figure 4), and showed that it was significantly increased in the frontal cortex (by $61.8 \pm 11.9 \%$; $P=0.009$ ), hippocampus (by $41.4 \pm 14.4 \% ; P=0.04$ ), and striatum (by $103.8 \pm 27.2 \% ; P=0.02$ ) (Figure 4 ).

These results indicated that GLT-1 upregulation occurred in the vicinity of mGluR $2 / 3$ receptors, thus suggesting that GLT-1 upregulation has a role in determining the reduced activation of mGluR2/3 observed in PPI experiments.

\section{DISCUSSION}

The major result of this study is that PPI alterations associated with GLT-1 upregulation are blocked by the selective mGluR2/3 agonist LY379268.
PPI of the startle reflex is a model of sensorimotor gating that is tested in a similar manner in humans and rats; for this reason, it is widely used to study the neurobiology of schizophrenia and the effects of medications (Geyer and Swerdlow, 1998; Dawson et al, 2000; Swerdlow et al, 2000; Geyer et al, 2001, 2002). Most importantly, although impaired startle PPI is shared by several neuropsychiatric diseases, it is consistently observed in schizophrenia, in which it is believed to be an index of the deficient sensorimotor gating underpinning sensory flooding and cognitive fragmentation (Braff and Geyer, 1990; Braff et al, 1992, 2001, 2007; Swerdlow et al, 1994, 2006; Minassian et al, 2007).

Rothstein et al (2005) showed that CEF robustly stimulates GLT-1 expression, but not that of the other glutamate transporters, through increased GLT-1 gene transcription. This finding has been replicated in different laboratories (eg, Chu et al, 2007; Ouyang et al, 2007; Lee et al, 2008), including ours (Bellesi et al, 2009; Omrani et al, 2009). We also showed that CEF increases GLT-1a expression in forebrain regions that regulate PPI of the startle (Bellesi et al, 2009). Whether CEF alters the expression of synaptically active molecules at nonglutamatergic synapses is currently unknown, although to date no evidence for an effect of CEF on other neurotransmitter system(s) has been published. As far as these results are concerned, it must be emphasized that, regardless of whether CEF acts on other transmitter systems, its effects on PPI are prevented by the GLT-1 antagonist DHK, indicating that GLT-1 upregulation is the major mediator of the effects of CEF on PPI. 
a
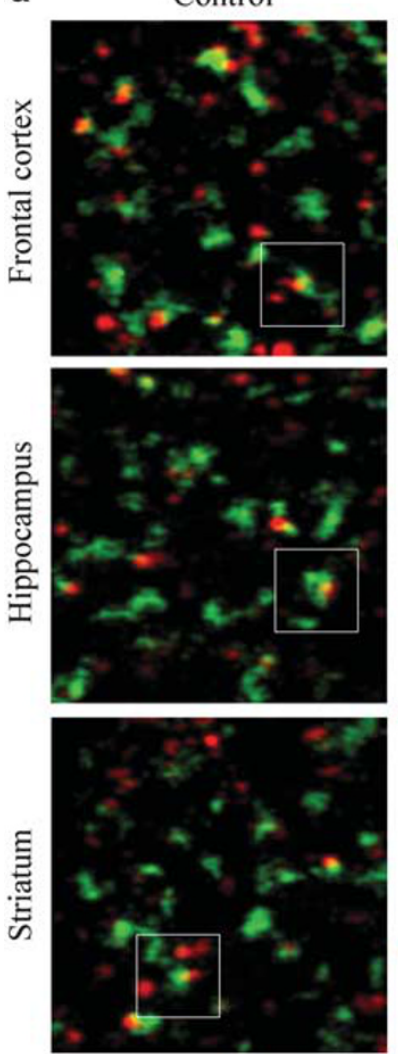

Ceftriaxone
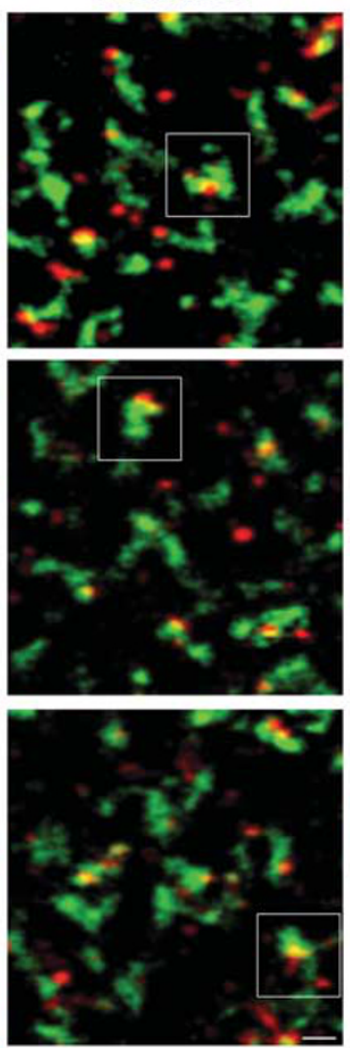
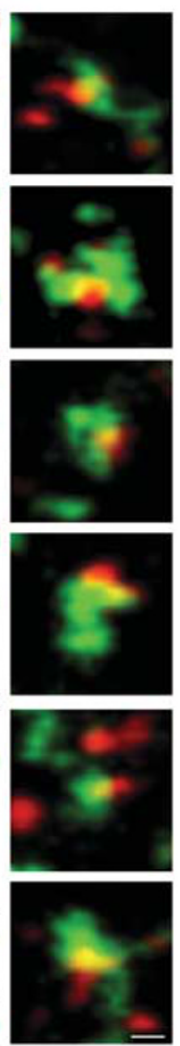

b
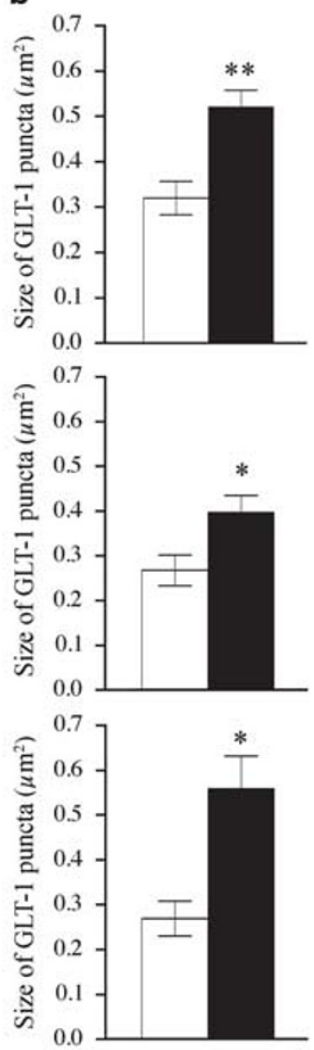

Figure 4 GLT-I upregulation occurs also in the vicinity of sites of mGluR2/3 expression in the frontal cortex, hippocampus, and striatum. (a) Doublelabeling studies showing GLT-I puncta (green) contacting mGluR2/3 puncta (red) in control and in CEF-treated rats. Framed regions are reproduced enlarged in the right column to illustrate that GLT-I puncta are larger in CEF-treated animals. Bar: $0.8 \mu \mathrm{m}$ in large frames and $0.4 \mu \mathrm{m}$ in small frames. (b) Quantitative evaluation of the size of GLT-I puncta contacting mGluR2/3 positive puncta in control (white columns) and CEF-treated (black columns) rats. Values are mean $\pm \mathrm{SEM}$. $* P<0.05$; $* * P<0.01$

In this paper, we showed that LY379268, a compound effective in animal models of schizophrenia (Cartmell et al, 1999, 2000; Clark et al, 2002; Imre et al, 2006; Imre, 2007), blocked PPI impairment associated with GLT-1 upregulation. Although the present findings do not allow predictions about clinical efficacy of LY379268, it is worth noting that the better assimilated analog LY404039 ameliorates both positive and negative symptoms in schizophrenia patients (Patil et al, 2007; Harrison, 2008). Some studies reported that LY379268 failed to block PPI alterations (but not other behavioral abnormalities) induced by administration of NMDA antagonists (Cartmell et al, 1999, 2000; Clark et al, 2002; Imre et al, 2006). The different results may be explained by the different paradigms used to impair PPI; indeed, it is conceivable that the reduction in glutamatergic transmission induced by NMDA antagonism is more intense than that induced by the upregulation of GLT-1, and that the modulating effect of LY379268 on glutamatergic transmission is not sufficient to restore PPI induced by NMDA antagonists.

The ability of LY379268 to prevent PPI abnormalities associated with GLT-1 upregulation suggests that the reduced activation of mGluR $2 / 3$ is a mechanism by which GLT-1 upregulation impairs PPI. mGluR2/3 activation depends on the spread of glutamate from release sites to the perisynaptic zone, where these receptors are predominantly located (Scanziani et al, 1997; Min et al, 1998; Mitchell and Silver,
2000; Ferraguti and Shigemoto, 2006); and GLT-1 controls extracellular levels of glutamate and it is mainly localized perisynaptically (Melone et al, 2009a). Thus, by modulating glutamate spillover, GLT-1 influences activation of mGluR2/3 (Rusakov and Kullmann, 1998; Barbour, 2001; Diamond, 2002; Tzingounis and Wadiche, 2007; Zheng et al, 2008; Omrani et al, 2009). Our western blotting and immunocytochemical studies are consistent with this view. First, we demonstrated that both expression and distribution of mGluR2/3 in forebrain regions regulating PPI were unchanged in CEF-treated rats compared with controls. Second, we showed that GLT-1 upregulation also occurred at the very sites where mGluR2/3 was expressed. To do this, we considered the overlap of fluorescence signals in double-labeled sections as a marker of nearness, a procedure validated by recent electron microscopy studies (Melone et al, 2009a). Upregulation of GLT-1 at sites close to those of mGluR2/3 expression may thus have a crucial role in reducing the amount of glutamate available for mGluR2/3 activation.

GLT-1 upregulation induced by CEF determines a strong, DHK-sensitive, impairment of mGluR-dependent LTD (Omrani et al, 2009). The possibility that a widespread impairment of LTD can induce cognitive alterations, including PPI abnormalities, has been investigated in animal models of schizophrenia. Mice lacking the dopamine transporter display PPI deficits (Ralph et al, 2001; Barr et al, 2004; Yamashita et al, 2006), and exhibit an impairment 
of hippocampal LTD (Morice et al, 2007). On these bases, it has been suggested that LTD could have a key role in modulating cognitive flexibility as well as in other complex cognitive functions (Morice et al, 2007; Nicholls et al, 2008). Therefore, it is possible that alterations of LTD observed in animals with GLT-1 upregulation (Omrani et al, 2009) are responsible for the alterations of the PPI described in this study, and may conceivably contribute to the cognitive impairment observed in schizophrenia patients.

\section{ACKNOWLEDGEMENTS}

This study was funded by grants from MIUR and Università Politecnica delle Marche to FC. We gratefully acknowledge A Frontini's assistance with confocal microscopy.

\section{DISCLOSURE}

The authors declare no conflict of interest.

\section{REFERENCES}

Andreasen NC (1997). Linking mind and brain in the study of mental illnesses: a project for a scientific psychopathology. Science 275: 1586-1593.

Andreasen NC (2000). Schizophrenia: the fundamental questions. Brain Res Brain Res Rev 31: 106-112.

Barbour B (2001). An evaluation of synapse independence. J Neurosci 21: 7969-7984.

Barr AM, Lehmann-Masten V, Paulus M, Gainetdinov RR, Caron MG, Geyer MA (2004). The selective serotonin-2A receptor antagonist M100907 reverses behavioral deficits in dopamine transporter knockout mice. Neuropsychopharmacology 29: 221-228.

Beart PM, O'Shea RD (2007). Transporters for L-glutamate: an update on their molecular pharmacology and pathological involvement. Br J Pharmacol 150: 5-17.

Bellesi M, Melone M, Gubbini A, Battistacci S, Conti F (2009). GLT-1 upregulation impairs prepulse inhibition of the startle reflex in adult rats. Glia 57: 703-713.

Braff DL, Geyer MA (1990). Sensorimotor gating and schizophrenia. Human and animal model studies. Arch Gen Psychiatry 47: 181-188.

Braff DL, Geyer MA, Swerdlow NR (2001). Human studies of prepulse inhibition of startle: normal subjects, patient groups, and pharmacological studies. Psychopharmacology (Berl) 156: 234-258.

Braff DL, Grillon C, Geyer MA (1992). Gating and habituation of the startle reflex in schizophrenic patients. Arch Gen Psychiatry 49: 206-215.

Braff DL, Light GA, Swerdlow NR (2007). Prepulse inhibition and P50 suppression are both deficient but not correlated in schizophrenia patients. Biol Psychiatry 61: 1204-1207.

Bragina L, Melone M, Fattorini G, Torres-Ramos M, VallejoIllarramendi A, Matute C et al (2006). GLT-1 down-regulation induced by clozapine in rat frontal cortex is associated with synaptophysin up-regulation. J Neurochem 99: 134-141.

Cartmell J, Monn JA, Schoepp DD (1999). The metabotropic glutamate $2 / 3$ receptor agonists LY354740 and LY379268 selectively attenuate phencyclidine versus d-amphetamine motor behaviors in rats. J Pharmacol Exp Ther 291: 161-170.

Cartmell J, Monn JA, Schoepp DD (2000). Attenuation of specific PCP-evoked behaviors by the potent mGlu2/3 receptor agonist, LY379268 and comparison with the atypical antipsychotic, clozapine. Psychopharmacology (Berl) 148: 423-429.
Chen W, Mahadomrongkul V, Berger UV, Bassan M, DeSilva T, Tanaka $\mathrm{K}$ et al (2004). The glutamate transporter GLT1a is expressed in excitatory axon terminals of mature hippocampal neurons. J Neurosci 24: 1136-1148.

Chu K, Lee ST, Sinn DI, Ko SY, Kim EH, Kim JM et al (2007). Pharmacological induction of ischemic tolerance by glutamate transporter-1 (EAAT2) upregulation. Stroke 38: 177-182.

Clark M, Johnson BG, Wright RA, Monn JA, Schoepp DD (2002). Effects of the mGlu2/3 receptor agonist LY379268 on motor activity in phencyclidine-sensitized rats. Pharmacol Biochem Behav 73: 339-346.

Conti F, Weinberg RJ (1999). Shaping excitation at glutamatergic synapses. Trends Neurosci 22: 451-458.

Danbolt NC (2001). Glutamate uptake. Prog Neurobiol 65: 1-105.

Danbolt NC, Pines G, Kanner BI (1990). Purification and reconstitution of the sodium- and potassium-coupled glutamate transport glycoprotein from rat brain. Biochemistry 29: 6734-6740.

Dawson ME, Schell AM, Hazlett EA, Nuechterlein KH, Filion DL (2000). On the clinical and cognitive meaning of impaired sensorimotor gating in schizophrenia. Psychiatry Res 96: 187-197.

Deng X, Shibata H, Ninomiya H, Tashiro N, Iwata N, Ozaki N et al (2004). Association study of polymorphisms in the excitatory amino acid transporter 2 gene (SLC1A2) with schizophrenia. BMC Psychiatry 4: 21.

Diamond JS (2002). A broad view of glutamate spillover. Nat Neurosci 5: 291-292.

Fattorini G, Melone M, Bragina L, Candiracci C, Cozzi A, Pellegrini Giampietro DE et al (2008). GLT-1 expression and Glu uptake in rat cerebral cortex are increased by phencyclidine. Glia 56: $1320-1327$.

Ferguson RE, Carroll HP, Harris A, Maher ER, Selby PJ, Banks RE (2005). Housekeeping proteins: a preliminary study illustrating some limitations as useful references in protein expression studies. Proteomics 5: 566-571.

Ferraguti F, Shigemoto R (2006). Metabotropic glutamate receptors. Cell Tissue Res 326: 483-504.

Geyer MA, Krebs-Thomson K, Braff DL, Swerdlow NR (2001). Pharmacological studies of prepulse inhibition models of sensorimotor gating deficits in schizophrenia: a decade in review. Psychopharmacology (Berl) 156: 117-154.

Geyer MA, Mcllwain KL, Paylor R (2002). Mouse genetic models for prepulse inhibition: an early review. Mol Psychiatry 7: 1039-1053.

Geyer MA, Swerdlow NR (1998). Measurement of startle response, prepulse inhibition, and habituation. In: Crawley JN, Skolnick P (eds). Current Protocols in Neuroscience. Wiley: New York. pp 8.7.1-8.7.157.

Harrison PJ (2008). Metabotropic glutamate receptor agonists for schizophrenia. Br J Psychiatry 192: 86-87.

Imre G (2007). The preclinical properties of a novel group II metabotropic glutamate receptor agonist LY379268. CNS Drug Rev 13: 444-464.

Imre G, Salomons A, Jongsma M, Fokkema DS, Den Boer JA, Ter Horst GJ (2006). Effects of the mGluR2/3 agonist LY379268 on ketamine-evoked behaviours and neurochemical changes in the dentate gyrus of the rat. Pharmacol Biochem Behav 84: 392-399.

Lauriat TL, McInnes LA (2007). EAAT2 regulation and splicing: relevance to psychiatric and neurological disorders. Mol Psychiatry 12: 1065-1078.

Lee SG, Su ZZ, Emdad L, Gupta P, Sarkar D, Borjabad A et al (2008). Mechanism of ceftriaxone induction of excitatory amino acid tranporter-2 expression and glutamate uptake in primary human astrocytes. J Biol Chem 283: 13116-13123.

Lewis DA, Gonzalez-Burgos G (2006). Pathophysiologically based treatment interventions in schizophrenia. Nat Med 12: 1016-1022.

Lewis DA, Moghaddam B (2006). Cognitive dysfunction in schizophrenia: convergence of gamma-aminobutyric acid and glutamate alterations. Arch Neurol 63: 1372-1376. 
Martinez ZA, Ellison GD, Geyer MA, Swerdlow NR (1999). Effects of sustained phencyclidine exposure on sensorimotor gating of startle in rats. Neuropsychopharmacology 21: 28-39.

Matute C, Melone M, Vallejo-Illarramendi A, Conti F (2005). Increased expression of the astrocytic glutamate transporter GLT-1 in the prefrontal cortex of schizophrenics. Glia 49: 451-455.

McCullumsmith RE, Meador-Woodruff JH (2002). Striatal excitatory amino acid transporter transcript expression in schizophrenia, bipolar disorder, and major depressive disorder. Neuropsychopharmacology 26: 368-375.

McGhie A, Chapman J (1961). Disorders of attention and perception in early schizophrenia. Br J Med Psychol 34: 103-116.

Melone M, Bellesi M, Conti F (2009a). Synaptic localization of GLT-1a in the rat somatic sensory cortex. Glia 57: 108-117.

Melone M, Bellesi M, Gubbini A, Conti F (2009b). GLT-1 upregulation enhances the effect of PCP on prepulse inhibition of the startle reflex in adult rats. Schizophr Res 109: 196-197.

Melone M, Bragina L, Conti F (2003). Clozapine-induced reduction of glutamate transport in the frontal cortex is not mediated by GLAST and EAAC1. Mol Psychiatry 8: 12-13.

Melone M, Burette A, Weinberg RJ (2005). Light microscopic identification and immunocytochemical characterization of glutamatergic synapses in brain sections. J Comp Neurol 492: 495-509.

Melone M, Vitellaro-Zuccarello L, Vallejo-Illarramendi A, PerezSamartin A, Matute C, Cozzi A et al (2001). The expression of glutamate transporter GLT-1 in the rat cerebral cortex is downregulated by the antipsychotic drug clozapine. Mol Psychiatry 6: 380-386.

Min MY, Rusakov DA, Kullmann DM (1998). Activation of AMPA, kainate, and metabotropic receptors at hippocampal mossy fiber synapses: role of glutamate diffusion. Neuron 21: 561-570.

Minassian A, Feifel D, Perry W (2007). The relationship between sensorimotor gating and clinical improvement in acutely ill schizophrenia patients. Schizophr Res 89: 225-231.

Minelli A, Barbaresi P, Reimer RJ, Edwards RH, Conti F (2001). The glial glutamate transporter GLT-1 is localized both in the vicinity of and at distance from axon terminals in the rat cerebral cortex. Neuroscience 108: 51-59.

Mitchell SJ, Silver RA (2000). Glutamate spillover suppresses inhibition by activating presynaptic mGluRs. Nature 404: 498-502.

Moghaddam B (2004). Targeting metabotropic glutamate receptors for treatment of the cognitive symptoms of schizophrenia. Psychopharmacology (Berl) 174: 39-44.

Morice E, Billard JM, Denis C, Mathieu F, Betancur C, Epelbaum J et al (2007). Parallel loss of hippocampal LTD and cognitive flexibility in a genetic model of hyperdopaminergia. Neuropsychopharmacology 32: 2108-2116.

Nicholls RE, Alarcon JM, Malleret G, Carroll RC, Grody M, Vronskaya S et al (2008). Transgenic mice lacking NMDARdependent LTD exhibit deficits in behavioral flexibility. Neuron 58: $104-117$.

Omrani A, Melone M, Bellesi M, Safiulina V, Aida T, Tanaka K et al (2009). Up-regulation of GLT-1 severely impairs LTD at mossy fibres-CA3 synapses. J Physiol 587: 4575-4588.

Ouyang YB, Voloboueva LA, Xu LJ, Giffard RG (2007). Selective dysfunction of hippocampal CA1 astrocytes contributes to delayed neuronal damage after transient forebrain ischemia. J Neurosci 27: 4253-4560.

Patil ST, Zhang L, Martenyi F, Lowe SL, Jackson KA, Andreev BV et al (2007). Activation of $\mathrm{mGlu} 2 / 3$ receptors as a new approach to treat schizophrenia: a randomized phase 2 clinical trial. Nat Med 13: 1102-1107.

Ralph RJ, Paulus MP, Fumagalli F, Caron MG, Geyer MA (2001). Prepulse inhibition deficits and perseverative motor patterns in dopamine transporter knock-out mice: differential effects of D1 and D2 receptor antagonists. J Neurosci 21: 305-313.
Rebuelto M, Ambros L, Rubio M (2003). Daily variations in ceftriaxone pharmacokinetics in rats. Antimicrob Agents Chemother 47: 809-812.

Rothstein JD, Dykes-Hoberg M, Pardo CA, Bristol LA, Jin L, Kuncl RW et al (1996). Knockout of glutamate transporters reveals a major role for astroglial transport in excitotoxicity and clearance of glutamate. Neuron 16: 675-686.

Rothstein JD, Patel S, Regan MR, Haenggeli C, Huang YH, Bergles DE et al (2005). Beta-lactam antibiotics offer neuroprotection by increasing glutamate transporter expression. Nature 433: 73-77.

Rusakov DA, Kullmann DM (1998). Extrasynaptic glutamate diffusion in the hippocampus: ultrastructural constraints, uptake, and receptor activation. J Neurosci 18: 3158-3170.

Rusakov DA, Lehre KP (2002). Perisynaptic asymmetry of glia: new insights into glutamate signalling. Trends Neurosci 25: 492-494.

Scanziani M, Salin PA, Vogt KE, Malenka RC, Nicoll RA (1997). Usedependent increases in glutamate concentration activate presynaptic metabotropic glutamate receptors. Nature 385: 630-634.

Shao L, Vawter MP (2008). Shared gene expression alterations in schizophrenia and bipolar disorder. Biol Psychiatry 64: 89-97.

Sheldon AL, Robinson MB (2007). The role of glutamate transporters in neurodegenerative diseases and potential opportunities for intervention. Neurochem Int 51: 333-355.

Smith RE, Haroutunian V, Davis KL, Meador-Woodruff JH (2001). Expression of excitatory amino acid transporter transcripts in the thalamus of subjects with schizophrenia. Am J Psychiatry 158: $1393-1399$.

Swerdlow NR, Braff DL, Geyer MA (2000). Animal models of deficient sensorimotor gating: what we know, what we think we know, and what we hope to know soon. Behav Pharmacol 11: 185-204.

Swerdlow NR, Braff DL, Taaid N, Geyer MA (1994). Assessing the validity of an animal model of deficient sensorimotor gating in schizophrenic patients. Arch Gen Psychiatry 51: 139-154.

Swerdlow NR, Geyer MA, Braff DL (2001). Neural circuit regulation of prepulse inhibition of startle in the rat: current knowledge and future challenges. Psychopharmacology (Berl) 156: 194-215.

Swerdlow NR, Light GA, Cadenhead KS, Sprock J, Hsieh MH, Braff DL (2006). Startle gating deficits in a large cohort of patients with schizophrenia: relationship to medications, symptoms, neurocognition, and level of function. Arch Gen Psychiatry 63: $1325-1335$.

Tanaka K, Watase K, Manabe T, Yamada K, Watanabe $\mathrm{M}$, Takahashi $\mathrm{K}$ et al (1997). Epilepsy and exacerbation of brain injury in mice lacking the glutamate transporter GLT-1. Science 276: $1699-1702$.

Testa CM, Friberg IK, Weiss SW, Standaert DG (1998). Immunohistochemical localization of metabotropic glutamate receptors mGluR1a and mGluR2/3 in the rat basal ganglia. J Comp Neurol 390: 5-19.

Tononi G, Edelman GM (2000). Schizophrenia and the mechanisms of conscious integration. Brain Res Brain Res Rev 31: 391-400.

Tzingounis AV, Wadiche JI (2007). Glutamate transporters: confining runaway excitation by shaping synaptic transmission. Nat Rev Neurosci 8: 935-947.

Vallejo-Illarramendi A, Torres-Ramos M, Melone M, Conti F, Matute C (2005). Clozapine reduces GLT-1 expression and glutamate uptake in astrocyte cultures. Glia 50: 276-279.

Venables PH (1960). The effect of auditory and visual stimulation on the skin potential response of schizophrenics. Brain 83: 77-92.

Yamashita M, Fukushima S, Shen HW, Hall FS, Uhl GR, Numachi Y et al (2006). Norepinephrine transporter blockade can normalize the prepulse inhibition deficits found in dopamine transporter knockout mice. Neuropsychopharmacology 31: 2132-2139.

Zheng K, Scimemi A, Rusakov DA (2008). Receptor actions of synaptically released glutamate: the role of transporters on the scale from nanometers to microns. Biophys J 95: 4584-4596. 